\title{
TOWARDS DIGITALIZATION IN THE CONSTRUCTION INDUSTRY WITH IMMERSIVE AND DRONES \\ TECHNOLOGIES: A CRITICAL LITERATURE REVIEW
}

\begin{abstract}
Purpose - Digital transformation in construction requires employing a wide range of various technologies. There is a significant progress of research in adopting technologies such as Unmanned Aerial Vehicles (UAVs), also known as drones, and immersive technologies in the construction industry over the last two decades. The purpose of this research is to assess the current status of employing UAVs and immersive technologies towards digitalizing the construction industry and highlighting the potential applications of these technologies, either individually or in combination and integration with each other.
\end{abstract}

Design/methodology/approach - In this study, a critical literature review was utilized in order to provide a clear review of the relevant existing studies. The literature was analyzed using the meta-synthesis technique to evaluate and integrate the findings in a single context.

Findings - The key findings are: (1) UAVs in conjunction with 4D BIM can be used to assess the project progress and compliance checking of geometric design models, (2) immersive technologies can be used to enable controlling construction projects remotely, applying/checking end users requirements, construction education and team collaboration. 
Practical implications - A detailed discussion around the application of UAVs and immersive technologies is provided. This is expected to support gaining an in-depth understanding of the practical applications of these technologies in industry.

Originality/value - The review contributes a needed common basis for capturing progress made in UAVs and immersive technologies to date and assessing their impact in construction projects. Moreover, this paper opens new horizon for novice researchers who will conduct research towards the digitalized construction.

Keywords - Literature review, digitalization, immersive technologies, Building Information Modelling, Unmanned Aerial Vehicles.

Paper type - Literature review

\section{Introduction}

Industries and sectors have been on evolution path for digitalization. Similarly, over the past decade, digitalization in the construction industry has been trending. The rapid development of information technology and systems has played a pivotal role in expediting the implementation of digitalization in industry (Elghaish et al., 2020). In particular, the constant increase in labour costs, along with the decreasing price of technologies, has encouraged the recent advance of new digitization processes and the movement to industry 4.0 (Golizadeh et al., 2018, Newman et al., 2020).

Building Information Modelling (BIM) was considered as a specialized tool for the industry just a decade ago and it is one of the main embodiments of digitalization (Howard and Björk, 2008). In addition to BIM, the adoption of more recent digital technologies such as Unmanned Aerial 
Vehicles (UAVs) and immersive technologies are becoming more popular in construction projects.

In particular, technologies related to UAVs, also known as drones, flying robots or Unmanned Aerial Systems (UAS) have experienced an unusual growth and have become much more affordable (Martinez et al., 2020). This makes many UAV-based applications possible for the automation of the construction process, such as information gathering (e.g., taking photos), surveying construction sites (Bang et al., 2017), monitoring construction progress, Liu et al. (2014) inspecting built infrastructure (Kim et al., 2015) and evaluating usability in relation to the safety assessment of the construction site (Gonçalves et al., 2017).

The construction industry has started to widely embrace immersive technologies, namely Virtual Reality (VR), Augmented Reality (AR) and Mixed Reality (MR). The concept of VR was established 50 years ago and it allows the replacement of a user's perception of the surrounding environment with a computer-generated artificial 3D environment (Zhou et al., 2012). AR technology integrates images of virtual elements into a real world. AR technology, with its capability, could enhance the user's perception of a virtual prototyping with real entities by connecting to the real world while maintaining the flexibility of the virtual world (Hou et al., 2013). To put it in a few words, the definition of VR and AR is based on the involvement of the visual sensations from the real world regardless of the establishment of immersion or the mechanisms of the display (Wolfartsberger, 2019). The combination of reality and virtuality can be defined as a MR. MR is a technology that blends real and virtual worlds to generate a brandnew environment where physical and digital objects can interact simultaneously (Chi et al., 2013). The tremendous potential of these immersive technologies could transform the ways in which construction companies consume and interact with information (Boton, 2018). 
The adoption of the aforementioned technologies is expected to lead to a better project delivery (Ammar et al., 2018), improved communication between stakeholders, informed decision making (Elghaish et al., 2019), reduced on site injuries and fatalities (Aghimien et al., 2019), and improved productivity (Leviäkangas et al., 2017). However, there is still little research that explores the potential applications of UAVs and immersive technologies, either individually or integrated with other technologies. Therefore, the aim of the research reported in this paper is to discuss the latest developments and applications of these technologies in the construction industry. Therefore, in this paper, the existing attempts as well as future trends are explored to help novice researchers find research gaps and understand the way those technologies can be correlated. Within the paper, the discussion of each digital technology will be structured as follows: (1) overview of the technology; (2) applications in the construction industry; and (3) key findings and conclusions.

\section{Methodology}

Webster and Watson (2002) state that the aim of the literature review is to address the research gap by identifying, evaluating and integrating the previous findings from relevant and similar studies. The mechanism of using the literature review in this paper is adopted in order to: (1) understand the progress achieved by other researchers to build the research base that can be used as a point of departure (Cohen et al., 2013); (2) build an integrated context that respects the arrangement between the different ideas while showing the contradiction between the theories in order to build a reliable argument (Saunders et al., 2016); (3) articulate specific statements and build arguments around each statement, using different views while linking them together in a single context. Epistemology is a philosophical term that discusses the nature, structure and scope of the knowledge, therefore, the epistemology explores the sources that shaped the knowledge such as perception, memory, and different types of reasoning (Goldman, 2004). One of the 
epistemological position is the Interpretivist that refers to discovering the reality from human views (human experience and perceptions) (Cohen and Manion, 1994). Therefore, the Interpretivist paradigm is used in this research to understand the contexts and beliefs that are socially constructed (Willis et al., 2007).

In this research a critical literature review was utilized in order to provide a clear review of the relevant studies pertaining to the proposed questions so as to explore the specific issue and fill the gap in a specific field of knowledge (Arbnor and Bjerke, 2008). Relevant publications were found using the online search, which is the dominant method of identifying the most relevant papers. Prominent journals and conferences were targeted in this step according to specific criteria, namely, the category of journals (Q1 and Q2) using Scopus classification and the date of the publication begins from 2008. The following major online databases were targeted for conference papers: IEEE, Thomson Reuter's Web of Science, ProQuest (ABI/INFORM), ScienceDirect (Elsevier) and Xplore. Different keywords were employed such as 'virtual reality in construction', 'augmented and mixed reality in construction', 'drones applications in construction' and 'health and safety using drones in construction'. After downloading the research papers from different sources, these papers were categorized in corresponding to different themes and sub-themes regarding immersive technologies and UAVs. Subsequently, the interpretive analytical techniques, more specifically, the critical and meta-synthesis techniques, were used to analyze the literature. The interpretive analytical techniques were used in this research as they are non-statistical techniques to evaluate and integrate the findings in a single context so as to identify the key elements in each study (Leary and Walker, 2018). Accordingly, after selecting the studies that were to be analyzed, they were listed in relation to each theme. Ultimately, the findings were summarized and interpreted in an integrated context (Brinkmann, 2013). 


\section{Unmanned Aerial Vehicle technologies}

\subsection{Potential applications and benefits}

UAVs are revolutionizing a wide range of construction activities through their advanced data collection capabilities (Asadi et al., 2020). UAV-based application surpasses conventional methods on construction sites in terms of accuracy, efficiency and cost effectiveness (Greenwood et al., 2019). However, there are still few publications that have explored the benefits of UAV in the construction industry. Initial research in this area has been largely exploratory, examining the potential application areas and the benefits of UAV capability. For example, Irizarry and Costa (2016) explored the potential benefits of a small-scale aerial drone for safety managers within the construction job-site. The results of this study led to recommendations for the required features of an ideal safety inspection drone. Liu et al. (2014) gave an overview of the state of UAV developments and their possible applications in civil engineering. This study presented a summary of the potential applications of UAV in seismic risk assessment, transportation, disaster response, construction management, surveying and mapping, and flood monitoring and assessment.

The research in this area remained very limited until 2016 when the number of annual publications became relatively significant, indicating that UAV research had come into its own as an independent research area. Irizarry and Costa (2016) presented an exploratory case study to identify the potential applications of visual assets obtained from UASs for construction management tasks. The results revealed the potential applications of UASs mainly for project progress monitoring, job-site logistics, evaluating safety conditions and making quality inspections, among other secondary management tasks. Goessens et al. (2018) aimed to prove the feasibility of building real-scale structures, in particular masonry structures, with big custom-built drones. In particular, the objective was to investigate drones' precision and their behavior while 
transporting, handling and laying loads, but also to draw up the first guidelines for the design of "drone-compatible" construction elements. The results show that using UAVs for the construction of future real-scale structures is certainly not a utopia and is very promising. However, further development is required, not only in terms of the drones themselves, but also regarding the transition from the laboratory stage to the construction of real structures with complex geometry, composed of slabs, walls, connections and finishing. Li et al. (2018) focused entirely on 3D pathplanning algorithms for drones in the indoor environment. In this study a novel approach to planning universal paths for drones in a known indoor environment using a voxel model was presented. This approach can make the drone fly at some distance from the obstacles by computing a 3D buffer around the obstacles, using our algorithm 3D, propagating approximate Euclidean distance transformation (3D PAEDT). Álvares et al. (2018) presented an exploratory study that aimed to assess the potential use of 3D mapping of buildings and construction sites using unmanned aerial-system (UAS) imagery for supporting construction-management tasks, based on two case studies developed in residential construction projects. The findings showed that 3D mapping from UAS imagery can offer a wide, fast and external view from different perspectives of the construction site, facilitated by greater interactivity between user and tool, as both $360^{\circ}$ viewing and the manipulation of 3D models are possible. Bogue (2018) discussed the role of drones and developments in autonomous ground vehicles and then presented different types of drones and their application areas in the construction industry with applications including the surveying of sites prior to the start of construction, the monitoring of project progress, stockpile and inventory monitoring, transport logistics, health and safety assessment and locating potential hazards, promotional photography and marketing. Goessens et al. (2018) study aimed to capture the merits of adopting UAS technology in the total life-cycle of a project by proposing a multidimensional framework that focused on four dimensions: life-cycle, managed object, 
potential role and stakeholder engagement. Similarly, the most recent study by Greenwood et al. (2019) provided a summary review of efforts related to UAV development with a focus on civilinfrastructure applications. In this study, highlights of recent achievements by UAVs in postdisaster reconnaissance, infrastructure-component monitoring, geotechnical engineering and construction management are presented. Lessons learned from UAV implementation and considerations for good practice are also discussed. Golizadeh et al. (2019) covered the topic of barriers to the adoption of RPAs, with an emphasis on the Australian context. Li and Liu (2019) investigated the current applications of multirotor drones, analyzed their benefits and explored their potential in the future of the construction industry. Kim et al. (2019a) evaluated human performance and identified the relationship between performance and experience to bring about a better understanding of the relationship between human performance and UAS usage.

\subsection{Automated surveying}

A traditional method of producing as-built information is for personnel to go on inspection rounds with printed check-lists and to take photographs for documentation (Frank, 2012). Afterwards, the newly gathered information should be put into files and models and transferred to contractors and all relevant staff (Kim et al., 2014). The efforts to maintain an updated model and schedule become increasingly complex with construction projects that are large in terms of spatial extent. Moreover, surveying applications rely mostly on labor-intensive GPS, Robotic Total Station (RTS), laser scanning and tachymetry (Barbarella et al., 2017). There are air- or space-borne technologies available, but their selection depends on the terrain and on the size of the area that must be surveyed (Oskouie et al., 2016). They are limited in range, very labor-intensive and costly, have potentially high measurement errors and time consuming in terms of performance (Tang et al., 2010). UAVs offer a potential solution to these concerns. Once UAV technology is proved to be accurate and 
reliable, it might assist or replace a specific segment in surveying applications (Siebert and Teizer, 2014). The earliest study found in this review that addresses the benefits of UAV in producing asbuilt was conducted by Siebert and Teizer (2014), who developed a novel approach for evaluating the performance of a newly designed as-built UAV system in test-bed and field-realistic environments. The evaluation in this study focused in particular on the magnitude of the errors in a UAV-based photogrammetric approach as compared with conventional surveying techniques used for ground truth measurements. There remained very little research in this particular field until the last two years when some studies were conducted to explore further the feasible use of UAV in automated surveying. Shazali and Tahar (2019) evaluated the geometric accuracy of a 3D model using UAV images. The results show that the errors between the actual measurement and the generated 3D model were less than $4 \mathrm{~cm}$. Moon et al. (2019) evaluated the potential and the usability of data integration by comparing the data processed through photogrammetry, based on laser scanning, with a focus on earthworks. This study proposed a method for generating and merging hybrid point cloud data acquired from laser scanning and UAV-based image processing. Freimuth and König (2018) focused on automating and improving the process of as-built data generation. A framework that employs autonomous UAVs as a means for the fully automatic acquisition of ordered and meaningful information on the state of structural objects was presented. The results show that the prototype of the proposed framework is capable of guiding a UAV around building structures, effectively enabling it to capture as-built information on an object level. Marmo et al. (2019) compared the original blueprints of the Basento River bridge with the photogrammetric survey carried out by UAV. The comparison clearly indicates a good agreement between the blueprints and the surveyed geometry and demonstrates the feasibility of the modern techniques, such as UAV, for carrying out as-is surveys. Finally, Park et al. (2019) proposed a framework for the automated registration of UAV and point clouds using 2D local feature points 
in images taken from UAVs and UGVs. This study identified the optimal angle at which to detect sufficient points matching the images taken by the point clouds. As a result, the study confirmed that full automation of spatial data collection and registration from a scattered environment (e.g., construction or disaster sites) by UAVs is feasible without human intervention.

\subsection{Information management and visualization}

UAVs are becoming an essential component of virtual design and construction (VDC), giving architects and engineers new and efficient ways to visualize and analyze structural requirements from the ground upwards. During the past two years, an increasing focus on integrating UAV technology to enhance information management and visualization was revealed in this review. Lu and Davis (2018) proposed a framework to integrate unordered images, geometric models and the surrounding environment on Google Earth using two major components: UAV-centric image alignment and processing, and a Keyhole Markup Language-based (KML) image and 3D modelmanagement system. The proposed system is aimed at providing construction engineers with a low-cost and low technology-barrier solution to representing a dynamic construction site through information management, integration and visualization. Puppala et al. (2018) developed the threedimensional models using UAV-based photogrammetry studies to provide the health conditions of the structure, with a focus on material performance. Different image datasets pertaining to the condition of various infrastructure assets were collected using a visual range camera mounted on the UAV. The 3D models were then developed to visualize the collected data and analyze the health conditions of the structure. Ajibola et al. (2019) developed a model that integrates a weighted averaging and additive median filtering algorithms to improve the accuracy and quality of the Digital Elevation Model (DEM) produced by UAV. Analysis of the result shows a remarkable increase of $88 \%$ in the accuracy of the fused DEM. Li and Liu (2019) presented 
improved neural networks to extract road information from remote-sensing images using a camera sensor equipped with UAV. Kim et al. (2019b) proposed a UAV-assisted robotic approach that can significantly reduce human intervention, as well as the time for data collection and processing, and provide technologies to enable cluttered environments to be frequently monitored, updated and analyzed so as to support timely decision-making. Ham and Kamari (2019) proposed a new method of automatically retrieving photo-worthy frames containing construction-related content that is scattered in collected video footages or consecutive images. The proposed automated method enables practitioners to assess the as-is status of construction sites efficiently through selective visual data, thereby facilitating data-driven decision-making at the right time.

\subsection{Monitoring, inspection and safety}

Construction managers, job superintendents and safety coordinators have more than enough on their hands when it comes to periodic inspections, job-site progress monitoring and keeping everyone safe on the job while focusing on delivering their projects on time and under budget (Ajibola et al., 2019). Although, when commercial drones can track and inspect a site faster, better and more accurately than a person ever could, surprisingly many construction professionals still inspect and monitor their sites in the old-fashioned way (Bosche and Haas, 2008).

Progress monitoring and acceptance of construction work are important tasks during the construction phase of a building. However, only three studies were found in this review that addressed the use of drones' applications in construction projects for monitoring purposes. Bang et al. (2017), proposed a method to generate a panorama of a construction site by using an image stitching technique, with a focus on preprocessing, to help managers identify various construction site conditions easily with the help of high-quality image data. Vick and Brilakis (2018) presented a novel model aimed at automatically detecting layered road design surfaces in unlabeled as-built 
point cloud data by using UAS. This was to generate a simulated aerial photogrammetry point cloud to test the performance of the proposed solution under ideal conditions. Kim and Kim (2018) proposed the use of a First Personal View (FPV) of a quadcopter drone as a tool for monitoring on-site status and communicating between construction participants.

There were very few studies found in this review which tackled the inspection issue in construction projects. (2017a)Kim et al. (2017) presented a crack identification strategy that combines hybrid image-processing with UAV technology. The proposed system in this study has been shown successfully to measure cracks thicker than $0.1 \mathrm{~mm}$ with a maximum length-estimation error of 7.3\%. Freimuth and König (2018) developed an application that integrates UAVs and BIM for visual inspection tasks. The authors developed an application that allows the operator to plan inspections in a 3D environment based on BIM data to trigger inspections automatically and to generate safe flight paths for the UAV. A recent study conducted by Ficapal and Mutis (2019) presented a framework for the detection, diagnosis and evaluation of thermal bridges in façade systems by using infrared thermography and a UAV. The framework approach focused on the evaluation of the general performance of the building envelope, including its actual state of deterioration, its obsolescence, energy consumption and functionality. Based on this foundation, the framework facilitates the definition of actions for retrofitting to make the best use of the existing structure and to determine possible scenarios.

Recently, there has been more focus on drones' applications in construction safety. Gheisari and Esmaeili (2019) conducted a usability study and a heuristic evaluation of a small-scale quadcopter equipped with a camera as a safety inspection tool on construction sites. They ultimately concluded that UASs could be an ideal safety-inspection assistant, providing a safety manager with voice interaction with construction workers and real-time access to videos or images from a range of 
predefined paths and locations around the job site. In another study, de Melo and Costa (2019) conducted two case studies to assess the applicability of UASs in collecting visual assets on the job site and evaluating the compliance of safety items according to safety regulations. More recent studies focusing on construction safety include Kim et al. (2019a), who present a UAV-assisted visual monitoring method that can automatically measure proximities among construction entities to serve as a proactive and applicable measure for safety intervention against struck-by hazards on construction sites and can ultimately promote a safer working environment for construction workers. Liu et al. (2019) proposed a safety-inspection method that integrates UAV and dynamic BIM. A dynamic BIM model is created by aggregating timely updated safety information with a BIM model in the Web environment. The synchronous navigation of UAV video and dynamic BIM is realized by matching the virtual camera parameters with the real ones. The proposed method enables the off-site managers to view the inspection video and make timely and comprehensive safety evaluations with the support of dynamic BIM. de Melo and Costa (2019) developed a conceptual framework for integrating the resilience engineering (RS) and UAS technology into construction projects to support the safety planning and control (SPC) process. This framework highlights the fact that UASs can be used to perform regular safety inspections which provide information to help managers' decision making, especially in tasks which involve a high risk of accidents, as well as promoting greater transparency. The visual assets collected with UASs can also be used for feedback about the SPC and to increase workers' awareness by means of safety training. Finally, Gheisari and Esmaeili (2019) conducted a survey study to determine the effectiveness and frequency of using UASs in improving safety operations or hazardous situations. The results indicated that the most important safety activities that could be improved using UASs were the monitoring of boom vehicles or cranes in the proximity of overhead power lines, monitoring activities in the proximity of boom vehicles or cranes and the monitoring of 
unprotected edges or openings. In terms of the UAS technical features required for safety inspection applications, the most important features were camera movability, sense-and-avoid capability and a real-time video communications feed.

\section{Immersive technologies}

\subsection{Project Control and monitoring}

Data retrieval allows construction workers to monitor a project against the building plan efficiently and to ensure successful completion. For example, immersive technologies allow users to see the building progress against schedule virtually. highlighted in their study that AR on tablet PC or mobile is the best option for monitoring and tracking a construction project. They also clarified how AR technology has the capability to facilitate the visualizing and estimating of the performed work on site and to compare it with the proposed schedule of the process. Park and Kim (2013) added another application to schedule monitoring by connecting AR material tracking to ensure that the necessary materials are on site. During an eight year period several studies focused on using immersive technologies in construction site monitoring to provide progress visualization directly on the site (Ratajczak et al., 2019).

Other studies focused on safety monitoring and proposed systems that combined immersive technologies and real-time tracking to improve the situational awareness of construction workers and to avoid hazardous situations (Cheng and Teizer, 2013, Kim et al., 2017). There were few studies found that focused on project scheduling. One was that by Kim et al. (2018), who developed an AR-based 4D CAD system which connects 4D and 5D objects with a real field image and an AR object to implement several types of schedule information, as well as to enable the use of constantly changing schedule information through AR objects. Another was by Ratajczak et al. 
(2019), who developed a unique field application that integrates a location-based management system (LBMS) into BIM and an AR platform so as to detect scheduling deviations easily by visualizing construction progress in $\mathrm{AR}$ and to provide daily progress information, as well as performance data, regarding the construction work, as well as context-specific information/documents on scheduled tasks.

\subsection{Facilities Management}

To date, no commonly accepted data model has been proposed to serve as the integrated data model to support facility operation. Although BIM models have gained increased acceptance in architecture engineering and construction activities, they are not fully adequate to support data exchange in the post-handover (operation) phase. Few studies were found that focused on dynamic data integrating to support facility management (FM) activities. Sampaio et al. (2012) presented two prototype applications to support the performance of periodic inspections and the monitoring of interior and exterior wall maintenance, using VR technology. Irizarry et al. (2013) developed a system called InfoSPOT as a mobile AR tool to support facility managers in accessing information about the facilities that they maintain. Williams et al. (2015) developed a fully automated BIM2MAR process to provide complex geometry on a computationally simplified mobile platform that would help facility managers to access real-time information with the AR environment updating automatically as changes were made to the BIM models to enable better decisions related to FM activities. Paulo Carreira et al. (2018) study focused on the implementation of a virtual reality environment prototype of a building management system using game engine technologies to handle and integrate data in a flexible and dynamic way, which is essential in management activities underlying FM. 


\subsection{Provision of Project Information On-Site}

The capabilities of immersive technologies to pool digital data and documentation with the physical view is a game-changer. Examples include Yeh et al. (2012), who presented a wearable device that could project the construction drawings and related information to help engineers to avoid carrying bulky construction drawings to the site and to reduce the effort required in looking for the correct drawings to obtain the information needed. Kim et al. (2018) developed the HD4AR system to facilitate the accurate exchange of project information among field personnel, using existing and already available camera-equipped mobile devices. Kim et al. (2013) developed a comprehensive system using mobile computing technology to provide construction stakeholders with a sufficient level of project information required for task management, including visualizing the task location in an AR environment. Chu et al. (2018) evaluated the effectiveness of BIM and AR system integration to enhance task efficiency through improving the information retrieval process during construction by developing a mobile BIM AR system with cloud-based storage capabilities.

\subsection{Team Collaboration and communication}

Construction projects involve collaboration between several project disciplines, including contractors, designers, managers and more. A successful partnership confirms that a project will be completed on time, as per the proposed budget. However, not all project teams involved in a project are always present on a job site. If any error occurs that requires immediate action to be agreed by all parties involved to review designs and make necessary changes, immersive technologies allow users to take notes and share video views of an error or design issue and to send information to remote teams in actual time. Pejoska et al. (2016) stated, in their study, that on-site project information accessibility and effective communication are significantly improving with the 
utilization of immersive technologies, as compared with more traditional information sources. However, some studies were found that focused on collaboration and communication in construction projects. For example, some studies focused on using immersive technologies to facilitate collaboration and communication between the design team. One is that by Goulding et al. (2012), who demonstrated the need for integrating collaborative design teams to facilitate project integration and interchange by applying a game environment supported by a web-based VR cloud platform to facilitate collaboration and decision making during the design process. Another is by Chalhoub and Ayer (2018), who examined the application of MR technologies in electrical construction design communication by comparing the performance of 18 electrical construction personnel who were tasked with building similar conduit assemblies using traditional paper. Du et al. (2018), meanwhile, developed a real-time synchronization system of BIM data in VR for collaborative decision-making. The system is based on an innovative cloud-based BIM metadata interpretation and communication method to allow users to update BIM model changes in VR headsets automatically and simultaneously.

Other studies focused more on facilitating communication between projects' parties, such as that by Lin et al. (2015), who proposed a visualized environment to facilitate the construction discussion process by using a stationary display called BIM Table for displaying public information and for collaboration among disciplines and by using AR technologies to connect the BIM Table and the mobile devices as well as the public and private information. Zaker and Coloma (2018) investigated the application of a VR-based workflow in a real project. A case study of VR integrated collaboration workflow was used to serve as an example of how AEC firms could overcome the challenge of collaboration between a project's teams, while Du et al. (2018) 
developed a cloud-based multi-user VR headset system called collaborative virtual reality (CoVR) that facilitates interpersonal project communication in an interactive VR environment.

\subsection{Training and Education}

VR-based training simulators are successfully employed in many industries (e.g., aviation) to help to train operators and professionals in a safe environment (Sacks et al., 2013). In the construction industry, there is a lot of machinery involved in the building process and this requires many hours of training. Immersive technologies allow construction workers to receive direct instructions and then to act accordingly (Zhao and Lucas, 2015). Additionally, immersive technologies can provide a safer training environment because construction workers can work with large machinery with a reduced risk of injury (Goulding et al., 2012). In this review, we found several studies that focused on the effectiveness of using immersive technologies in avoiding exposure to hazardous job sites and provided recommendations for better safety training programs (Albert et al., 2014, Shi et al., 2019). Other studies focused on developing immersive technology-based systems to provide students and construction workers with real practical and safety experiences (Pedro et al., 2016, Sacks et al., 2013, Le et al., 2015). To avoid the high costs and the time associated with VR technologies, researchers started to investigate the use of 360 VR to simulate construction safety challenges. A 360-degree VR delivers a panoramic view of a real-world environment with a high sense of presence (Portalés et al., 2018). In contrast to traditional VR, 360 VR offers fast digital job site generation, easy-to produce simulations and high levels of realism due to the inherent photography techniques used in this technology.

Immersive technologies are improving the speed and quality of training, allowing distant experts to be present (Sacks et al., 2013). Such technologies have demonstrated the potential to provide education for construction and workforce development by conducting a simulation of accessibility 
design review and assessment for a tiny house via VR and MR mock-ups with the participation of both student novices and professional experts Wu et al. (2019). In the same vein, Costa et al. (2019) focused on bridging the gap between experts and new employees by using AR technology combined with a layer of simulated visualizations to enhance the new employee's spatial and temporal understanding of complex construction processes.

However, in this context, the education of construction workers, managers and students was the most common purpose of the reviewed immersive technology studies. Several studies focused on education for construction students by presenting the importance of using immersive technologies and non-traditional methods in teaching building construction courses (Shanbari et al., 2016, Shirazi and Behzadan, 2015, Bosché et al., 2016, Zhao et al., 2016, Hou et al., 2017, González, 2018, Wang et al., 2018, Bashabsheh et al., 2019, Meža et al., 2014).

\subsection{Quality management}

Immersive technology solutions are playing a key role in enabling quality management in construction projects and offering defect detection much earlier in the project lifecycle by coordinating multiple 3D models (Zhao and Lucas, 2015). This is better than using a 2D screen where it is easy to overlook issues. The application of immersive technologies also saves costs and time by helping to catch potential issues in the virtual world before something is built (Portalés et al., 2018). Examples of studies focusing on quality management in construction using immersive technologies are as follows: Hou et al. (2015) developed an AR system to improve productassembly productivity and performance by lowering cognitive workload via AR; Fazel and Izadi (2018) developed an affordable interactive multi-marker augmented reality tool for constructing free-form modular surfaces to enhance the accuracy and quality of construction; Ahn et al. (2019) proposed a novel approach for visualizing vital information within a user's field of view during 
manufacturing processes at shops and offered considerations for implementing projection-based AR in practice; Mirshokraei et al. (2019) presented a web-based system aimed at enhancing quality management during the execution phase of structural elements by integrating building-information modeling (BIM) and AR technology; Costa et al. (2019) proposed a spatial augmented reality system that could leverage BIM standards to orchestrate the necessary tasks automatically and help the operator to tack weld the beam attachments so as to ensure maximum flexibility during the beam-assembly stage and to improve overall product quality.

Other studies focused on defect management and developed inspection tools to control construction quality, such as: Kwon et al. (2014), who developed a system that combined BIM, image-matching and AR technologies to improve construction defect management and perform quality management efficiently; Hernández et al. (2018), who developed building self-inspection techniques using AR and BIM technologies to support construction workers in self-inspection processes with the overall objective of controlling the quality of construction work in order to ensure that specifications are implemented according to the design; and Portalés et al. (2018), who developed an AR-based interactive tool to help to make the process of pre-fab building inspection a seamless one, allowing the inspectors to document the process digitally with images and 3D data in addition to traditional measurements and annotations.

\section{Discussion and Key Findings}

In this section, the main findings from the critical/meta-analysis of the reviewed literature are presented. As shown in Figure 1, four areas of applications of immersive technologies and two main areas of the applications of UAVs were observed from the analysis of the extant literature review. 


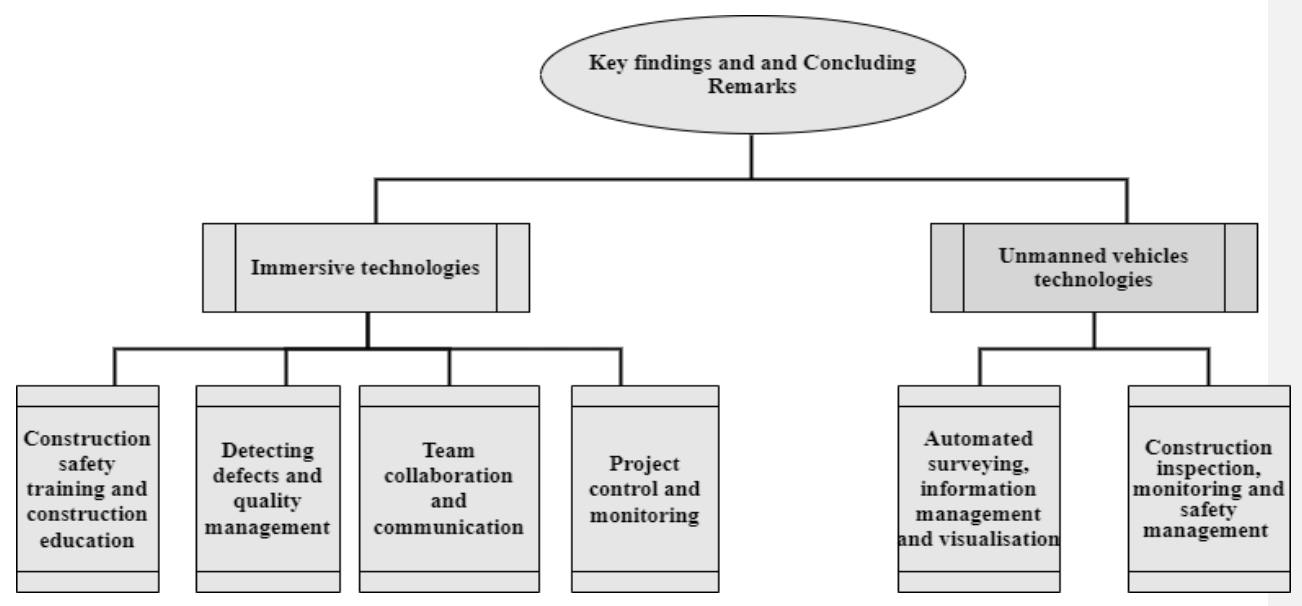

Figure 1. Identified areas of applications of immersive technologies and UAVs

\subsection{Immersive technologies}

Many construction management tools are currently integrating with immersive technologies to increase the output rate. There are five areas of applications classified according to the number of existing publications and the potential applications. These areas are as follows:

- Construction safety training and construction education are the most popular research areas for immersive technologies in construction with 37 articles (35\% of the total reviewed articles). The large moral and financial burden caused by construction accidents, coupled with on-site safety-training hazards, demand innovative new approaches to safety. The studies vary in objectives, technology and scope, yet all consistently report positive results from safety interventions using immersive technologies. Further studies should be conducted as follows: (1) to highlight risks and on-site difficulties long before site-work begins, enabling these to be avoided or mitigated; (2) to quantify the direct impact on accident reduction, analyze the long-term learning effects of immersive-technology 
training platforms and address the computational and cost limitations of immersive technologies' development.

- The defect and quality management with 24 articles $(22.6 \%$ of the total reviewed articles). The continuous financial implications of rework in construction caused by quality issues, coupled with the high cost of on-site inspections, initiated the need for new technologies to enhance construction quality and facilitate inspection processes. Yet there is a need for more research that focuses on: (1) pre-fabricated or modular construction to ensure better quality and fewer defects; (2) use of immersive technology to facilitate the process of material submittals which require the architect and engineer to verify that the correct products are being installed.

- Team collaboration and communication with 19 articles (18\% of the total). Effective communication and collaboration between construction-project parties is one of the most important prerequisites of a successful construction project. For instance, the initial design requires the active participation of not just the contractors, but the clients as well: a VR headset can facilitate the proposed layout visualization and allow valuable discussion between the project's parties. Nevertheless, there are very few studies focusing on communication and collaboration during the pre-planning stages. There is a need for more research on the use of immersive technologies to facilitate collaboration between the project's parties in direct relation to the proposed concept in order to avoid misunderstandings and errors and to provide valuable input on the most complex details of the project in much more detail than either 2D drawings, or even 3D BIM models, can provide.

- Project control and monitoring with 17 articles (16\% of the total). AR has enhanced the scheduling aspect of the construction projects significantly; it is able to show an as-planned 
vs. an as-built form to allow visualization of progress. Moreover, AR is used in project scheduling and project progress-tracking in the modern construction process. However, there is a need for more research to focus on the use of AR for solving on-site construction challenges, such as differing site conditions and design defects and errors, before they are encountered in the field, thus avoiding changes and reducing delays attendant to such situations. The least popular research areas are those of on-site project information with five articles (4.7\% of the total) and facilities management with four articles (3.7\%). This indicates that more research studies are required to focus on the application of immersive technologies in these two areas.

\subsection{Unmanned Aerial Vehicle technologies}

UAVs' application in the construction industry is a relatively new innovation. Their initial use was mainly exploratory, examining the application areas, the benefits and the feasibility of UAV capability. This piloting phase is reflected in the initial research, starting around 2012. But it was not until 2018 that the number of annual academic articles became relatively significant, reaching double digits, indicating that UAV research had started to become an independent research area. Yet, research remains limited in both quantity and content focus and the amount of studies related to UAVs in the construction industry is expected to rise exponentially in the future (Gheisari and Esmaeili, 2019). To date, UAV-based applications have focused on some prevailing themes.

Regarding the existing applications of UAV, automated surveying, information management and visualization and construction inspection, monitoring and safety management are initially employed. However, we noticed in our review that the focus of UAVs within the construction industry - the implementation process - has remarkably been ignored. One example is the study conducted by Greenwood et al. (2019), which focused on developing the technical capabilities of 
UAVs in interaction with other technologies or with humans. Another example is the study conducted by Golizadeh et al. (2019), which focused on the lack of technical experience among construction practitioners in terms of using UAVs in construction activities. These studies serve as examples of how the existing research has focused on the technical aspects of UAVs' applications rather than on the implementation process for UAVs in the construction industry. Accordingly, research focusing on the implementation of UAVs and on the barriers limiting their utilization in the construction industry is needed (Golizadeh et al., 2019). Judging by the analysis of influential research areas, little has been done in terms of site management which includes monitoring, inspection and safety.

However, further studies are needed to provide more in-depth exploration of the utilization of UAVs in construction-site management. Moreover, more studies focusing on the feasibility of using UAVs in construction projects are needed to clarify the extent of disruption to existing practices brought on by UAVs' introduction and to look at the associated costs. Moreover, the integration of UAV technology within the broader construction operation, and the interface with other technologies, also needs to be explored further.

\section{Conclusion}

This paper presents a critical evaluation of the digitalization tools that are employed to move towards digitalization in construction. Two main technologies were critically discussed in this research, namely, UAV technologies and immersive technologies. Each topic was analyzed individually to appraise the capabilities and weakness points, as well as, integrations between these technologies to provide various solutions were also evaluated. As such, this research can direct researchers, particularly, early researchers to find the extant gap in each area, as well as, recommended solutions that can be developed by integrating these technologies. 
The analysis of extant literature review refers that there is a progress of implementing MR in integration with BIM to track project progress; employing drones to scan the construction sites and compare the captured images with $4 \mathrm{D}$ BIM to measure the progress. As such, there is a progress in integrating these technologies to enhance the delivery of construction projects, however, most of researchers highlighted that the provided solutions need to be tested using large case studies to measure the scalability of provided solutions.

The statistical analysis of the existing research in corresponding to the main four areas of applications of immersive technologies refers that utilization of these technologies for health and safety and detecting defects and quality management got a significant attention from researchers the last decade, meanwhile, other two areas of applications, namely, Team collaboration and communication and Project control and monitoring require to be heavily investigated in the future in order to maximize the advantages of immersive technologies in the construction industry.

Even though the utilization of unmanned vehicles were introduced in a few research, particularly, for 'Automated surveying, information management and visualization' and 'Construction inspection, monitoring and safety management', however, more research are needed to validate all mentioned/proposed utilizations of these technologies (i.e. case studies research).

Given the critical analysis of literature review was conducted based on predominate solutions (i.e. UAVs, immersive technologies), therefore, systematic analysis according to years of publications could not be considered as the objective of this research is to define gaps that prevent maximizing digitalizing the construction industry, not assessing the research status of these industry technologies. However, this limitation will be considered in future research. 


\section{References}

AGHIMIEN, D. O.AIGBAVBOA, C. O.OKE, A. E. and THWALA, W. D. (2019), "Mapping out research focus for robotics and automation research in construction-related studies". Journal of Engineering, Design and Technology. pp.10.1108/JEDT-09-2019-0237

AHN, S.HAN, S. and AL-HUSSEIN, M. (2019), "2D drawing visualization framework for applying projection-based augmented reality in a panelized construction manufacturing facility: Proof of concept". Journal of Computing in Civil Engineering, Vol. 33 No. 5. pp.10.1061/(ASCE)CP.1943-5487.0000843

AJIBOLA, I. I.MANSOR, S.PRADHAN, B. and SHAFRI, H. Z. M. (2019), "Fusion of UAV-based DEMs for vertical component accuracy improvement". Measurement, Vol. 147. pp. 106795.10.1016/j.measurement.2019.07.023

ALBERT, A.HALLOWELL, M. R.KLEINER, B.CHEN, A. and GOLPARVAR-FARD, M. (2014), "Enhancing construction hazard recognition with high-fidelity augmented virtuality". Journal of Construction Engineering and Management, Vol. 140 No. 7. pp.10.1061/(ASCE)C0.19437862.0000860

ÁLVARES, J. S.COSTA, D. B. and DE MELO, R. R. S. (2018), "Exploratory study of using unmanned aerial system imagery for construction site 3D mapping". Construction Innovation, Vol. 18 No. 3. pp. 301-320.10.1108/CI-05-2017-0049

AMMAR, M.RUSSELLO, G. and CRISPO, B. (2018), "Internet of Things: A survey on the security of IoT frameworks". Journal of Information Security and Applications, Vol. 38. pp. 827.10.1016/j.jisa.2017.11.002

ARBNOR, I. and BJERKE, B. 2008. Methodology for creating business knowledge, London, UK, SAGE Publications.1446202526

ASADI, K.SURESH, A. K.ENDER, A.GOTAD, S.MANIYAR, S.ANAND, S.NOGHABAEI, M.HAN, K.LOBATON, E. and WU, T. (2020), "An integrated UGV-UAV system for construction site data collection". Automation in Construction, Vol. 112.pp. 103068.10.1016/j.autcon.2019.103068

BANG, S.KIM, H. and KIM, H. (2017), "UAV-based automatic generation of high-resolution panorama at a construction site with a focus on preprocessing for image stitching". Automation in Construction, Vol. 84. pp. 70-80.10.1016/j.autcon.2017.08.031

BARBARELLA, M.DE BLASIIS, M. R. and FIANI, M. (2017), "Terrestrial laser scanner for the analysis of airport pavement geometry". International Journal of Pavement Engineering, Vol. 20 No. 4. pp. 1-15.10.1080/10298436.2017.1309194

BASHABSHEH, A. K.ALZOUBI, H. H. and ALI, M. Z. (2019), "The application of virtual reality technology in architectural pedagogy for building constructions". Alexandria Engineering Journal, Vol. 58 No. 2. pp. 713-723.10.1016/j.aej.2019.06.002

BOGUE, R. (2018), "What are the prospects for robots in the construction industry?". Industrial Robot: An International Journal, Vol. 45 No. 1. pp.10.1108/IR-11-2017-0194

BOSCHÉ, F.ABDEL-WAHAB, M. and CAROZZA, L. (2016), "Towards a mixed reality system for construction trade training". Journal of Computing in Civil Engineering, Vol. 30 No. 2. pp. 04015016.10.1061/(ASCE)CP.1943-5487.0000479

BOSCHE, F. and HAAS, C. T. (2008), "Automated retrieval of 3D CAD model objects in construction range images". Automation in Construction, Vol. 17 No. 4. pp. 499512.10.1016/j.autcon.2007.09.001

BOTON, C. (2018), "Supporting constructability analysis meetings with Immersive Virtual Realitybased collaborative BIM 4D simulation". Automation in Construction, Vol. 96. pp. 115.10.1016/j.autcon.2018.08.020

BRINKMANN, S. 2013. Qualitative interviewing: Understanding qualitative research New York, USA, Oxford University Press.0199861390 
CHALHOUB, J. and AYER, S. K. (2018), "Using Mixed Reality for electrical construction design communication". Automation in Construction, Vol. 86. pp. 1-10.10.1016/j.autcon.2017.10.028

CHENG, T. and TEIZER, J. (2013), "Real-time resource location data collection and visualization technology for construction safety and activity monitoring applications". Automation in Construction, Vol. 34. pp. 3-15.10.1016/j.autcon.2012.10.017

CHI, H.-L.KANG, S.-C. and WANG, X. (2013), "Research trends and opportunities of augmented reality applications in architecture, engineering, and construction". Automation in Construction, Vol. 33. pp. 116-122.10.1016/j.autcon.2012.12.017

CHU, M.MATTHEWS, J. and LOVE, P. E. (2018), "Integrating mobile building information modelling and augmented reality systems: an experimental study". Automation in Construction, Vol. 85. pp. 305-316.10.1016/j.autcon.2017.10.032

COHEN, L.MANION, L. and MORRISON, K. 2013. Research methods in education, London, UK, Routledge.113572203X

COSTA, C. M.ROCHA, L. F.MALACA, P.COSTA, P. G.MOREIRA, A. P.TAVARES, P.SOUSA, A. and VEIGA, G. (2019), "Collaborative welding system using BIM for robotic reprogramming and spatial augmented reality". Automation in Construction, Vol. 106. pp. 112.10.1016/j.autcon.2019.04.020

DE MELO, R. R. S. and COSTA, D. B. (2019), "Integrating resilience engineering and UAS technology into construction safety planning and control". Engineering, Construction and Architectural Management, Vol. 26 No. 11. pp.10.1108/ECAM-12-2018-0541

DU, J.SHI, Y.ZOU, Z. and ZHAO, D. (2018), "CoVR: Cloud-based multiuser virtual reality headset system for project communication of remote users". Journal of Construction Engineering and Management, Vol. 144 No. 2. pp. 040171091- 0401710919.10.1061/(ASCE)CO.19437862.0001426

ELGHAISH, F.ABRISHAMI, S. and HOSSEINI, M. R. (2020), "Integrated project delivery with blockchain: An automated financial system". Automation in Construction, Vol. 114. pp. 116.10.1016/j.autcon.2020.103182

ELGHAISH, F.ABRISHAMI, S.HOSSEINI, M. R.ABU-SAMRA, S. and GATERELL, M. (2019), "Integrated project delivery with BIM: An automated EVM-based approach". Automation in Construction, Vol. 106. pp.10.1016/j.autcon.2019.102907

FAZEL, A. and IZADI, A. (2018), "An interactive augmented reality tool for constructing free-form modular surfaces". Automation in Construction, Vol. 85. pp. 135145.10.1016/j.autcon.2017.10.015

FICAPAL, A. and MUTIS, I. (2019), "Framework for the Detection, Diagnosis, and Evaluation of Thermal Bridges Using Infrared Thermography and Unmanned Aerial Vehicles". Buildings, Vol. 9 No. 8. pp. 179.10.3390/buildings 9080179

FRANK, G. C. 2012. Construction quality: Do it right or pay the price, New Jersey, USA, Pearson Higher Education, Inc.0133002837

FREIMUTH, H. and KÖNIG, M. (2018), "Planning and executing construction inspections with unmanned aerial vehicles". Automation in Construction, Vol. 96. pp. 540553.0.1016/j.autcon.2018.10.016

GHEISARI, M. and ESMAEILI, B. (2019), "Applications and requirements of unmanned aerial systems (UASs) for construction safety". Safety science, Vol. 118. pp. 230240.10.1016/j.ssci.2019.05.015

GOESSENS, S.MUELLER, C. and LATTEUR, P. (2018), "Feasibility study for drone-based masonry construction of real-scale structures". Automation in Construction, Vol. 94. pp. 458480.10.1016/j.autcon.2018.06.015

GOLIZADEH, H.HON, C. K.DROGEMULLER, R. and HOSSEINI, M. R. (2018), "Digital engineering potential in addressing causes of construction accidents". Automation in Construction, Vol. 95. pp. 284-295.10.1016/j.autcon.2018.08.013 
GOLIZADEH, H.HOSSEINI, M. R.EDWARDS, D. J.ABRISHAMI, S.TAGHAVI, N. and BANIHASHEMI, S. (2019), "Barriers to adoption of RPAs on construction projects: a task-technology fit perspective". Construction Innovation. pp.10.1108/CI-09-2018-0074

GONÇALVES, P.SOBRAL, J. and FERREIRA, L. A. (2017), "Unmanned aerial vehicle safety assessment modelling through petri nets". Reliability Engineering \& System Safety, Vol. 167. pp. 383393.10.1016/j.ress.2017.06.021

GONZÁLEZ, N. A. A. (2018), "Development of spatial skills with virtual reality and augmented reality". International Journal on Interactive Design and Manufacturing (IJIDeM), Vol. 12 No. 1. pp. 133144.10.1007/s12008-017-0388-x

GOULDING, J.NADIM, W.PETRIDIS, P. and ALSHAWI, M. (2012), "Construction industry offsite production: A virtual reality interactive training environment prototype". Advanced Engineering Informatics, Vol. 26 No. 1.pp. 103-116.10.1016/j.aei.2011.09.004

GREENWOOD, W. W.LYNCH, J. P. and ZEKKOS, D. (2019), "Applications of UAVs in civil infrastructure". Journal of Infrastructure Systems, Vol. 25 No. $2 . \quad$ pp. 04019002.10.1061/(ASCE)IS.1943-555X.0000464

HAM, Y. and KAMARI, M. (2019), "Automated content-based filtering for enhanced vision-based documentation in construction toward exploiting big visual data from drones". Automation in Construction, Vol. 105. pp.10.1016/j.autcon.2019.102831

HERNÁNDEZ, J. L.MARTÍN LERONES, P.BONSMA, P.VAN DELFT, A.DEIGHTON, R. and BRAUN, J.-D. (2018), "An IFC interoperability framework for self-inspection process in buildings". Buildings, Vol. 8 No. 2. pp. 32.10.3390/buildings 8020032

HOU, L.CHI, H.-L.TARNG, W.CHAI, J.PANUWATWANICH, K. and WANG, X. (2017), "A framework of innovative learning for skill development in complex operational tasks". Automation in Construction, Vol. 83. pp. 29-40.10.1016/j.autcon.2017.07.001

HOU, L.WANG, X.BERNOLD, L. and LOVE, P. E. (2013), "Using animated augmented reality to cognitively guide assembly". Journal of Computing in Civil Engineering, Vol. 27 No. 5. pp. 439451.10.1061/(ASCE)CP.1943-5487.0000184

HOU, L.WANG, X. and TRUIJENS, M. (2015), "Using augmented reality to facilitate piping assembly: An experiment-based evaluation". Journal of Computing in Civil Engineering, Vol. 29 No. 1. pp.10.1061/(ASCE)CP.1943-5487.0000344

HOWARD, R. and BJÖRK, B.-C. (2008), "Building information modelling-Experts' views on standardisation and industry deployment". Advanced Engineering Informatics, Vol. 22 No. 2. pp. 271-280.10.1016/j.aei.2007.03.001

IRIZARRY, J. and COSTA, D. B. (2016), "Exploratory study of potential applications of unmanned aerial systems for construction management tasks". Journal of Management in Engineering, Vol. 32 No. 3. pp. 05016001

IRIZARRY, J.GHEISARI, M.WILLIAMS, G. and WALKER, B. N. (2013), "InfoSPOT: A mobile Augmented Reality method for accessing building information through a situation awareness approach". Automation in Construction, Vol. 33. pp. 11-23.10.1016/j.autcon.2012.09.002

KIM, C.PARK, T.LIM, H. and KIM, H. (2013), "On-site construction management using mobile computing technology". Automation in Construction, Vol. 35 . pp. 415423.10.1016/j.autcon.2013.05.027

KIM, D.LIU, M.LEE, S. and KAMAT, V. R. (2019a), "Remote proximity monitoring between mobile construction resources using camera-mounted UAVs". Automation in Construction, Vol. 99. pp. 168-182.10.1016/j.autcon.2018.12.014

KIM, H.LEE, J.AHN, E.CHO, S.SHIN, M. and SIM, S.-H. (2017), "Concrete crack identification using a UAV incorporating hybrid image processing". Sensors, Vol. 17 No. 9. pp. 2052.10.3390/s17092052

KIM, H. S.KIM, S.-K.BORRMANN, A. and KANG, L. S. (2018), "Improvement of realism of 4D objects using augmented reality objects and actual images of a construction site". KSCE Journal of Civil Engineering, Vol. 22 No. 8. pp. 2735-2746.10.1007/s12205-017-0734-3 
KIM, J.-W.KIM, S.-B.PARK, J.-C. and NAM, J.-W. (2015), "Development of crack detection system with unmanned aerial vehicles and digital image processing". Advances in structural engineering and mechanics (ASEM15). pp. 25-29.10.1061/(ASCE)CF.1943-5509.0001185

KIM, M.-K.SOHN, H. and CHANG, C.-C. (2014), "Automated dimensional quality assessment of precast concrete panels using terrestrial laser scanning". Automation in Construction, Vol. 45. pp. 163177

KIM, P.PARK, J.CHO, Y. K. and KANG, J. (2019b), "UAV-assisted autonomous mobile robot navigation for as-is 3D data collection and registration in cluttered environments". Automation in Construction, Vol. 106. pp. 102918.10.1016/j.autcon.2019.102918

KIM, S. and KIM, S. (2018), "Opportunities for construction site monitoring by adopting first personal view (FPV) of a drone". Smart Structures and Systems, Vol. 21 No. 2. pp. 139149.10.12989/sss.2018.21.2.139

KWON, O.-S.PARK, C.-S. and LIM, C.-R. (2014), "A defect management system for reinforced concrete work utilizing BIM, image-matching and augmented reality". Automation in construction, Vol. 46. pp. 74-81.10.1016/j.autcon.2014.05.005

LE, Q. T.PEDRO, A. and PARK, C. S. (2015), "A social virtual reality based construction safety education system for experiential learning". Journal of Intelligent \& Robotic Systems, Vol. 79 No. 3-4. pp. 487-506.10.1007/s10846-014-0112-z

LEARY, H. and WALKER, A. (2018), "Meta-analysis and meta-synthesis methodologies: Rigorously piecing together research". TechTrends, Vol. 62 No. 5. pp. 525-534.10.1007/s11528-0180312-7

LEVIÄKANGAS, P.PAIK, S. M. and MOON, S. (2017), "Keeping up with the pace of digitization: The case of the Australian construction industry". Technology in Society, Vol. 50. pp. 3343.10.1016/j.techsoc.2017.04.003

LI, F.ZLATANOVA, S.KOOPMAN, M.BAI, X. and DIAKITÉ, A. (2018), "Universal path planning for an indoor drone". Automation in Construction, Vol. 95.9 pp. 275283.10.1016/j.autcon.2018.07.025

LI, Y. and LIU, C. (2019), "Applications of multirotor drone technologies in construction management". International Journal of Construction Management, Vol. 19 No. 5. pp. 401412.10.1080/15623599.2018.1452101

LIN, T.-H.LIU, C.-H.TSAI, M.-H. and KANG, S.-C. (2015), "Using augmented reality in a multiscreen environment for construction discussion". Journal of Computing in Civil Engineering, Vol. 29 No. 6. pp. 04014088.10.1061/(ASCE)CP.1943-5487.0000420

LIU, D.CHEN, J.HU, D. and ZHANG, Z. (2019), "Dynamic BIM-augmented UAV safety inspection for water diversion project". Computers in Industry, Vol. 108. pp. 163177.10.1016/j.compind.2019.03.004

LIU, P.CHEN, A. Y.HUANG, Y.-N.HAN, J.-Y.LAI, J.-S.KANG, S.-C.WU, T.-H.WEN, M.-C. and TSAI, M.-H. (2014), "A review of rotorcraft unmanned aerial vehicle (UAV) developments and applications in civil engineering". Smart Struct. Syst, Vol. 13 No. 6. pp. 10651094.10.12989/sss.2014.13.6.1065

LU, X. and DAVIS, S. (2018), "Priming effects on safety decisions in a virtual construction simulator". Engineering, Construction and Architectural Management, Vol. 25 No. 2. pp. 273294.10.1108/ECAM-05-2016-0114

MARMO, F.DEMARTINO, C.CANDELA, G.SULPIZIO, C.BRISEGHELLA, B.SPAGNUOLO, R.XIAO, Y.VANZI, I. and ROSATI, L. (2019), "On the form of the Musmeci's bridge over the Basento river". Engineering Structures, Vol. 191. pp. 658-673.10.1016/j.engstruct.2019.04.069

MARTINEZ, J. G.GHEISARI, M. and ALARCÓN, L. F. (2020), "UAV integration in current construction safety planning and monitoring processes: Case study of a high-rise building construction project in Chile". Journal of Management in Engineering, Vol. 36 No. 3. pp.10.1061/\%28ASCE\%29ME.1943-5479.0000761 
MEŽA, S.TURK, Ž. and DOLENC, M. (2014), "Component based engineering of a mobile BIM-based augmented reality system". Automation in onstruction, Vol. 42. pp. 112.10.1016/j.autcon.2014.02.011

MIRSHOKRAEI, M.DE GAETANI, C. I. and MIGLIACCIO, F. (2019), "A web-based BIM-AR auality management system for structural elements". Applied Sciences, Vol. 9 No. 19. pp.10.3390/app9193984

MOON, D.CHUNG, S.KWON, S.SEO, J. and SHIN, J. (2019), "Comparison and utilization of point cloud generated from photogrammetry and laser scanning: 3D world model for smart heavy equipment planning". Automation in Construction, Vol. 98.9 p. 322331.10.1016/j.autcon.2018.07.020

NEWMAN, C.EDWARDS, D.MARTEK, I.LAI, J.THWALA, W. D. and RILLIE, I. (2020), "Industry 4.0 deployment in the construction industry: A bibliometric literature review and UK-based case study". Smart and Sustainable Built Environment. pp.10.1108/SASBE-02-2020-0016

OSKOUIE, P.BECERIK-GERBER, B. and SOIBELMAN, L. (2016), "Automated measurement of highway retaining wall displacements using terrestrial laser scanners". Automation in Construction, Vol. 65. pp. 86-101.10.1016/j.autcon.2015.12.023

PARK, C.-S. and KIM, H.-J. (2013), "A framework for construction safety management and visualization system". Automation in Construction, Vol. 33. pp. 95103.10.1016/j.autcon.2012.09.012

PARK, J.KIM, P.CHO, Y. K. and KANG, J. (2019), "Framework for automated registration of UAV and UGV point clouds using local features in images". Automation in Construction, Vol. 98. pp. 175182.10.1016/j.autcon.2018.11.024

PAUlO CARREIRACASTElO, T.gOMES, C. C.FERREIRA, A.RIBEIRO, C. and COSTA, A. A. (2018), "Virtual reality as integration environments for facilities management: Application and users perception". Engineering, Construction and Architectural Management, Vol. 25 No. 1. pp.10.1108/ECAM-09-2016-0198

PEDRO, A.LE, Q. T. and PARK, C. S. (2016), "Framework for integrating safety into construction methods education through interactive virtual reality". Journal of Professional Issues in Engineering Education and Practice, Vol. 142 No. 2. pp.10.1061/(ASCE)EI.19435541.0000261

PEJOSKA, J.BAUTERS, M.PURMA, J. and LEINONEN, T. (2016), "Social augmented reality: Enhancing context-dependent communication and informal learning at work". British Journal of Educational Technology, Vol. 47 No. 3. pp. 474-483.10.1111/bjet.12442

PORTALÉS, C.CASAS, S.GIMENO, J.FERNÁNDEZ, M. and POZA, M. (2018), "From the paper to the tablet: On the design of an AR-based tool for the inspection of pre-fab buildings. Preliminary results of the SIRAE project". Sensors, Vol. 18 No. 4. pp. $1262.10 .3390 / s 18041262$

PUPPALA, A. J.CONGRESS, S. S.BHEEMASETTI, T. V. and CABALLERO, S. R. (2018), "Visualization of civil infrastructure emphasizing geomaterial characterization and performance". Journal of Materials in Civil Engineering, Vol. 30 No. 10. pp. 04018236.10.1061/(ASCE)MT.19435533.0002434

RATAJCZAK, J.RIEDL, M. and MATT, D. T. (2019), "BIM-based and AR Application combined with location-based management system for the improvement of the construction performance". Buildings, Vol. 9 No. 5. pp. 118.10.3390/buildings 9050118

SACKS, R.PERLMAN, A. and BARAK, R. (2013), "Construction safety training using immersive virtual reality". Construction Management and Economics, Vol. 31 No. 9. pp. 10051017.10.1080/01446193.2013.828844

SAMPAIO, A.ROSÁRIO, D. and GOMES, A. (2012), "Monitoring interior and exterior wall inspections within a virtual environment". Advances in Civil Engineering, Vol. 2012. pp.10.1155/2012/780379 
SAUNDERS, M.LEWIS, P. and THORNHILL, A. 2016. Research methods for business students, Harlow, UK, Pearson Education.9780273716860

SHANBARI, H.BLINN, N. and ISSA, R. R. (2016), "Using augmented reality video in enhancing masonry and roof component comprehension for construction management students". Engineering, Construction and Architectural Management, Vol. 23 No. 6. pp. 765-781.10.1108/ECAM-012016-0028

SHAZALI, A. S. A. and TAHAR, K. N. (2019), "Virtual 3D model of Canseleri building via close-range photogrammetry implementation". International Journal of Building Pathology and Adaptation, Vol. 38 No. 1. pp. 217-227.10.1108/IJBPA-02-2018-0016

SHI, Y.DU, J.AHN, C. R. and RAGAN, E. (2019), "Impact assessment of reinforced learning methods on construction workers' fall risk behavior using virtual reality". Automation in Construction, Vol. 104. pp. 197-214.10.1016/j.autcon.2019.04.015

SHIRAZI, A. and BEHZADAN, A. H. (2015), "Content delivery using Augmented Reality to enhance students' performance in a building design and assembly project". Advances in Engineering Education, Vol. 4 No. 3. pp.

SIEBERT, S. and TEIZER, J. (2014), "Mobile 3D mapping for surveying earthwork projects using an Unmanned Aerial Vehicle (UAV) system". Automation in construction, Vol. 41. pp. 114.10.1016/j.autcon.2014.01.004

TANG, P.HUBER, D. and AKINCI, B. (2010), "Characterization of laser scanners and algorithms for detecting flatness defects on concrete surfaces".Journal of Computing in Civil Engineering, Vol. 25 No. 1.pp. 31-42.10.1061/ASCECP.1943-5487.0000073

VICK, S. and BRILAKIS, I. (2018), "Road design layer detection in point cloud data for construction progress monitoring". Journal of Computing in Civil Engineering, Vol. 32 No. 5. pp.10.1061/(ASCE)CP.1943-5487.0000772

WANG, C.LI, H. and KHO, S. Y. (2018), "VR-embedded BIM immersive system for QS engineering education". Computer Applications in Engineering Education, Vol. 26 No. 3. pp. 626$641.10 .1002 /$ cae.21915

WEBSTER, J. and WATSON, R. T. (2002), "Analyzing the past to prepare for the future: Writing a literature review". MIS quarterly. pp. xiii-xxiii

WILLIAMS, G.GHEISARI, M.CHEN, P.-J. and IRIZARRY, J. (2015), "BIM2MAR: An efficient BIM translation to mobile augmented reality applications". Journal of Management in Engineering, Vol. 31 No. 1.pp.10.1061/(ASCE)ME.1943-5479.0000315

WOLFARTSBERGER, J. (2019), "Analyzing the potential of Virtual Reality for engineering design review". Automation in Construction, Vol. 104. pp. 27-37.10.1016/j.autcon.2019.03.018

WU, W.HARTLESS, J.TESEI, A.GUNJI, V.AYER, S. and LONDON, J. (2019), "Design assessment in virtual and mixed reality environments: Comparison of novices and experts". Journal of Construction Engineering and Management, Vol. 145 No. 9. pp.10.1061/(ASCE)C0.1943-7862.0001683

YEH, K.-C.TSAI, M.-H. and KANG, S.-C. (2012), "On-site building information retrieval by using projection-based augmented reality". Journal of Computing in Civil Engineering, Vol. 26 No. 3. pp. 342-355.10.1061/(ASCE)CP.1943-5487.0000156

ZAKER, R. and COLOMA, E. (2018), "Virtual reality-integrated workflow in BIM-enabled projects collaboration and design review: a case study". Visualization in Engineering, Vol. 6 No. 1. pp.10.1186/s40327-018-0065-6

ZHAO, D. and LUCAS, J. (2015), "Virtual reality simulation for construction safety promotion". International journal of injury control and safety promotion, Vol. 22 No. 1. pp. 5767.10.1080/17457300.2013.861853

ZHAO, D.MCCOY, A.KLEINER, B. and FENG, Y. (2016), "Integrating safety culture into OSH risk mitigation: A pilot study on the electrical safety". Journal of Civil Engineering and Management, Vol. 22 No. 6. pp. 800-807.10.3846/13923730.2014.914099 
ZHOU, J.LEE, I.THOMAS, B.MENASSA, R.FARRANT, A. and SANSOME, A. (2012), "In-situ support for automotive manufacturing using spatial augmented reality". International Journal of Virtual Reality, Vol. 11 No. 1. pp. 33-41.10.20870/IJVR.2012.11.1.2835 